\title{
'Stray appetites': a socio-ecological analysis of free-ranging dogs living alongside human communities in Bangalore, India
}

\author{
Shireen Jagriti Bhalla ${ }^{1}$ (D) Roy Kemmers $^{1}$ (D) Ana Vasques $^{1}$ (D) $\cdot$ Abi Tamim Vanak ${ }^{2,3,4}$ (ID)
}

Accepted: 5 January 2021 / Published online: 16 February 2021

(C) The Author(s) 2021

\begin{abstract}
Across the developing world, humans and free-ranging domestic dogs share common spaces. The relationship between these dogs and humans can range from one of dependence, to apathy, to conflict. Given the high number of humans attacked by dogs every year in India, and the lack of an effective population control strategy, we seek to provide insights into the conflict and propose alternative population management options based on reducing the carrying capacity of the environment. We used a mixed methods approach to understand both ecological and sociological underpinnings of free-ranging dog-human relationships in Bangalore, India. We conducted a photographic capture-recapture survey of free-ranging dogs to estimate population size and linked it to the availability of potential food sources. We also conducted a qualitative survey to assess attitudes of residents towards the dog population. We found that dog population varied from 192 to 1888 per square kilometre across a gradient of housing densities. The density of houses, bakeries and garbage piles were significant predictors of dog population size. Crucially, as low as 10 to $18 \%$ of houses supported the large population of dogs, highlighting the need for residents to act responsibly towards the dogs. Further, we found that garbage, although significant, is a secondary food source to household-maintained dogs. Since on the whole, respondents expressed the desire for a reduction in dog population, we suggest decreasing the carrying capacity of the environment by targeting these three food sources.
\end{abstract}

Keywords Free-ranging dog populations $\cdot$ Food sources $\cdot$ Socio-economic groups $\cdot$ Attitudes

\section{Introduction}

Free-ranging dogs are an integral component of the urban ecology of Indian cities. Current estimates put the total Indian free-ranging dog population at roughly 59 million (Gompper 2014). The term 'stray dog' in this paper is used synonymously with free-ranging dog (FRD) which is defined by Beck (1973) as "Any dog observed without human supervision on public property or on private property with

Roy Kemmers, Ana Vasques and Abi Tamim Vanak contributed equally to this work.

Shireen Jagriti Bhalla

sjagritib@gmail.com

1 Erasmus University College, Rotterdam, The Netherlands

2 Ashoka Trust for Research in Ecology and the Environment, Bengaluru, India

3 DBT/Wellcome Trust India Alliance Fellow, Hyderabad, India

4 School of Life Sciences, University of KwaZulu-Natal, Durban, South Africa immediate unrestrained access to public property" (p. 3). These dogs play several roles in the urban environment. In developing countries, Reese (2005) found that they keep trash and vermin levels down and provide companionship to people. However, they are also prone to aggression, are noisy, and are carriers of diseases - predominantly rabies. Research on the ecology of free-ranging dogs is essential for informing policy on the management of their populations, in order to reduce the risk of diseases and attacks.

About 20 million people in India are estimated to be bitten by animals every year, $91.5 \%$ of which are dogs, and 60 $63.6 \%$ of those are free-ranging (Sudarshan et al. 2006). This amounts to roughly 12 million free-ranging dog bites a year. Hampson et al. (2015) estimated an annual incidence of 20,847 human deaths to rabies in India, which is roughly $35 \%$ of all global deaths due to rabies. This is a decrease from the 30,000 annual deaths reported for the period of 1990-2002. Sudarshan et al. (2007) attributed this to an absolute increase in the socio-economic (SE) status of the Indian population, greater awareness and better access to treatment. However, other reports have noted that there has been a steady increase in the number of dog bite cases (KIMS 2007; Menezes 2008). 
There is a generally acknowledged paucity of data on the subject, and neglect in the management of the disease, indicating a lack of investment by the government in the matter. The disease has been neglected partly because deaths are scattered - three-quarters of rabies deaths occur in rural areas - and it is not seen as a health crisis, unlike other epidemics (Chatterjee 2009). Another reason is because there is a lack of coordination and a comprehensive national strategy to tackle the issue, unlike in Sri Lanka and Thailand which have made more significant progress in battling rabies (Sudarshan et al. 2007). Recently, however, the Indian media has been picking up coverage of dog-related incidents, and public pressure for more effective control of dogs is mounting.

In terms of population control, national law since 2001 stipulates that free-ranging dogs can only be controlled through the Animal Birth Control policy, also called the ABC program (Animal Welfare Board of India 2001). This task is delegated to local authorities and involves capturing the dogs, taking them to a pound where they are sterilised and immunised, and returning them to the same locality where they were found. There has been little systematic verification of the success of the ABC program, but there are doubts as to its feasibility because of the high number of dogs that would need to be sterilised for there to be any sizable effect on the population (Belsare and Vanak 2020; Totton et al. 2010). Coleman and Dye (1996) published a theoretical model stating that at least $70 \%$ of the total dog population would have to be vaccinated in a short period of time to eliminate or prevent rabies on at least $96.5 \%$ of occasions. This was echoed in research conducted around the ABC program in Jodhpur, by Totton et al. (2010) who performed population and demographic studies in 2005 and 2007, before and after the implementation of the $\mathrm{ABC}$ program. They found that over the two years, $61.8-86.5 \%$ of the free-ranging population was sterilised and vaccinated. They predicted that by maintaining that level of $\mathrm{ABC}$ intervention, the dog population would decrease by $69 \%$ after $13-18$ years and vaccination coverage would stabilise at over $70 \%$. However, there has been no longterm data on any of the $\mathrm{ABC}$ programmes, making it difficult to assess the actual success of the ABC strategy (Belsare and Vanak 2020).

In the Indian city of Bangalore which is the setting for this study, the $\mathrm{ABC}$ programme can reliably be considered unsuccessful. The most recent official free-ranging dog census, conducted in 2019, estimated the number at just over 0.3 million, compared to a human population of around 12 million (Worldwide Veterinary Service Centre, as reported by Sharma 2019). The census found that $46 \%$ of the free-ranging $\operatorname{dog}_{\mathrm{s}}$ in the city had not undergone the $\mathrm{ABC}$ programme. The report explained that the population had increased sharply from the 0.185 million dogs found in a 2013 census by the city's administrative body - the Bruhat Bangalore Mahanagara Palike (BBMP).
Given the inadequacy of the sterilisation method, interventions premised on reducing the carrying capacity of the environment have been proposed. Totton et al. (2010) suggested that in addition to the $\mathrm{ABC}$ program, we must reduce the available food in the environment to assist in controlling the population. Baquero et al. (2016) found that the latter is the most effective way to influence dog populations, compared to changing rates of abandonment, adoption, sterilisation and changing the carrying capacity of domestic dogs. This approach has been mildly echoed in several articles and directives which have proposed that the public can contribute to managing the population by not dumping waste in public (Herbert et al., 2012; KIMS 2007; Reese 2005) and by regulating slaughterhouses dumping waste (KIMS 2007). However, these directives operate on the assumption that refuse is the primary food source of free-ranging dogs. Meanwhile, other researchers propose that over $80 \%$ of freeranging dogs in urban areas of developing countries depend on 'reference households' or 'reference individuals' which support the bulk of the free-ranging population through direct feeding (Belsare and Gompper 2013; Cliquet et al. 2007; Morters et al. 2014; Reese 2005). Due to the sustained dependence of these dogs on specific houses, they are sometimes referred to as 'owned' dogs, despite being allowed to roam freely (Morters et al. 2014). The third proposed source is commercial areas which carry high quantities of organic material. Reese (2005) proposes that in North India there might be enough food sources from 'food markets, slaughterhouses, temples and roadside restaurants' to sustain the dogs. Yet, the nutritional dependence on the different food sources has not been quantified, because as Morters et al. (2014) have stated, quantifying the "uptake of environmental resources is generally not practicable" (p. 1097).

With a focus on further investigating the potential for this line of interventions in Bangalore, we pose the first research question of the study, 'How can we predict free-ranging dog population sizes based on different types offood sources?' We seek to identify the role played by garbage piles, households and commercial establishments, respectively.

Given the tight-interconnectedness between humans and free-ranging dogs, Matter and Daniels (2000) state that the most important determinant of dog population size is the attitude of the relevant communities. Similarly, any interventions that could be based on food sources would involve community-level changes. This requires a more in-depth understanding of community practices and opinions with respect to free-ranging dogs. However, the lack of data on strays extends to public opinion, which is primarily captured in the media, and therefore does not present a comprehensive view of attitudes, limiting the inputs to the framing of policy. While the media often reports opinions of upper-class residents, the perspectives of those who live closer to the dogs and are thereby affected more by them, is lacking. An exception is a 
paper by Herbert et al. (2012), who interviewed residents of slums - which see a disproportionate number of rabies cases from dog bites. They found that $66.5 \%$ of slum respondents saw free-ranging dogs as a problem, because they bark and create a nuisance $(37.3 \%)$ and attack and bite people (29.2\%). Most respondents felt that the duty of the dog population control is largely that of the governments. The authors suggested that this lack of a feeling of responsibility for the problem could mean that people are not aware of the part they can play by for example, avoiding dumping food waste (Herbert et al., 2012).

As Reese (2005) said, "the success of such control measures depends heavily on an understanding of the dog ecology and the nature of the dog-human bond in the locale under consideration." (p. 58). Without an understanding of the anthropological context within which interventions might be suggested, possible ecological interventions are limited in their practicability. Therefore, in addition to this paper being an ecological study, in it we aim to build upon the knowledge of attitudes towards dogs, of residents from different socio-economic classes in Bangalore. To do so we pose the second research question 'What are the differences in opinions on the free-ranging dog-human conflict across socioeconomic groups of the Indian urban public? Further, how can these differences be understood?'

\section{Methods - ecology of free-ranging dogs}

In order to answer the first research question regarding how different types of food sources can be used to predict the population of dogs, we collected raw data on the distribution of dogs and food sources, and ran a generalized linear analysis with multi-model inference. In this section, the process of data collection, organisation and analysis is described.

\section{Data collection}

\section{Location}

The data regarding dog populations and food sources was collected in northern Bangalore, India, spread over the localities of Jakkur, RK Hegde Nagar, Amruthahalli, Sahakar Nagar, Kodigehalli and Thindlu (Fig. S1). These were urban areas, characterised by differences in density and socioeconomic profile, which were also captured to ensure a representative sampling. Localities were mostly homogenous in SE profile and somewhat spread out over $14.1 \mathrm{~km}^{2}$ of North Bangalore. Sampling units were chosen if nearly the entire unit reflected their SE classification. The clustering of units that can be seen in Fig. S1, was for ease of sampling.

\begin{tabular}{ll}
\hline Locality & Units + Classifications \\
\hline Jakkur & 2 Lower \\
RK Hegde Nagar & 2 Empty, 6 Lower, 2 Middle \\
Amruthahalli & 1 Lower \\
Sahakar Nagar & 3 Empty, 7 Upper \\
Kodigehalli & 1 Upper \\
Thindlu & 4 Middle \\
\hline
\end{tabular}

\section{Unit areas}

The spatial scale used in the study was $248 * 248 \mathrm{~m}^{2}$. This was deemed appropriate based on existing data concerning the maximum home range of free-ranging dogs in India, which one study found to be $544 \mathrm{~m}$ in diameter (Pal et al., 1998). Spatial resolution twice as fine was therefore considered adequate to capture the dynamics of dog distribution in relation to food sources.

QGIS version 3.4.3-1 (QGIS Development Team 2018) was used to create the $248 * 248 \mathrm{~m}^{2}$ grid map which was imported onto GoogleMyMaps for use while surveying the dogs. 28 units, each with fairly homogenous socio-economic class profiles, were selected for survey.

\section{SE class classification}

It is important to note that economic status is difficult to gauge accurately without income data. Moreover, most neighbourhoods experience gentrification at some point and are not entirely homogeneous. But because the sample areas were on the outskirts of the city, the character of a neighbourhood was relatively singular and easy to characterise. The classification was made as follows:

(a) Lower socio-economic class: small houses with no cars or only company-owned taxis (the resident being the taxi driver) parked outside $(n=9)$.

(b) Middle class: small independent houses without space for cars. If present, the cars were low-end models and parked out on the street $(n=6)$.

(c) Upper class: large independent houses with one or more personal cars either in driveways or parked outside $(n=8)$.

(d) Empty: areas where housing development was just beginning. Largely characterised by sparsely interspersed upper-class houses, makeshift houses of construction workers and empty plots of land $(n=5)$. 


\section{Dog population survey}

A free-ranging dog population survey was conducted using photographic capture-recapture sampling method (Karanth et al., 2004; Tiwari et al., 2018). This technique involves repeated sampling of a population, wherein the individuals are recognised in each subsequent sampling not by artificial physical marks but by comparison with pictures from previous sightings. The surveys were conducted by moving at a steady speed on a bicycle through all the streets in the unit area and recording sightings using the mobile application Geopaparazzi. The route followed in each unit was chosen based on the most efficient way to cover every single street and remained the same in each subsequent sampling. In this program for each sighting, an image of the dog was captured along with its location. At the end of each sampling session, a .kmz file was exported for processing on Google Earth Pro which displays the locations of each dog photographed in a sample, along with the images. Four surveys were conducted in each unit over the span of two consecutive days, in the morning between 630 and 930 and in the evening between 1500 and 1800 . Only in the case of one unit, the number of samples was three rather than four, because the weather impeded one sampling session. These times allow for enough light for photography and have been found by other authors to produce the highest number of dog encounters (Tiwari et al. 2018). The surveys took place between 16 January and 22 January 2019 with 1796 sightings recorded. Of these, 761 individual dogs were identified, with 324 being 'uniques' or dogs that were only sighted once in total. The full dataset is presented in Table S1.

\section{Food source mapping}

The routes used in the dog survey were subsequently covered by bicycle again and Geopaparazzi was used to mark the location and nature of each food source present. For the garbage piles, in addition to the location, an image was taken for further analysis. The sources fell into six categories, namely (a) garbage, (b) small roadside shops, (c) bakeries, (d) butcher/ fish shops, (e) restaurants, and (f) houses. The last food source - houses - was numbered using the base print of buildings in Google Maps. Since the surveys were conducted in predominantly residential areas and the number of commercial establishments were few in comparison, all the building base prints were counted without checking whether they represented a commercial or residential unit. Likewise, in the entire area surveyed, there were only four small apartment buildings counted, and each was counted as one house since the number of households within were unknown.

The shops, bakeries, meat/fish shops and restaurants were marked as potential food sources as it was hypothesised that dogs would either be able to find food in garbage bins or, in the case of shops and bakeries, might be fed scraps by the proprietors and consumers. The different types of establishments were analysed separately. The food source dataset is presented in full in Table S2.

\section{Data curation}

\section{Data count}

The dog survey data were imported as .kmz files onto Google Earth Pro and the images from each sampling session were used to map the dogs to each other to identify the number of unique individuals. Each dog was pinned at the first location it was seen and the number of repetitive sightings recorded. Typically, dogs were seen only within one unit, however if they were seen over multiple units, they were coded in the unit they were first sighted in. When the images were unclear, an informed judgement was made based on proximity and knowledge of the dogs. This data were reduced to a list of (a) total number of dogs spotted in a unit and (b) number of dogs that had only been spotted once, i.e., uniques (Table S1).

\section{Population estimates}

The Application SuperDuplicates online tool was used to make probability estimates of the population based on the raw data (Chao et al., 2017). Tiwari et al. (2018) and Tiwari et al. (2019) found this to be the most efficient tool for estimating free-ranging populations in urban and rural India. This tool makes use of the number of uniques observed in an area to extrapolate the number of undetected individuals. While it was initially created to estimate species richness, in this study, each dog is considered as a unique species, as done by Tiwari et al. (2019), to procure a reliable minimum population estimate. The application offers the use of 'incidence data' where one inputs the number of observed dogs, the number of uniques (dogs spotted only once) and the number of sampling units (4 for all except 1$)$. The population estimate produced under chao.2est was used as the final population in the analysis (Table S1).

\section{Garbage selection and sizing}

For a garbage pile to be considered a viable source, it was visually assessed for recent organic matter. This was to distinguish those that could be reliable food sources from garbage piles that were either inactive or created during construction and that contained primarily inorganic matter. Where garbage piles lined a road bordering a sampling unit, they were included in the unit's analysis. However, garbage piles in neighbouring sampling units were discounted for the sake of clarity.

The viable garbage sources were recoded by size since there were large differences in that regard. Garbage piles that 
measured between $2 * 2 \mathrm{~m}^{2}$ and $4 * 4 \mathrm{~m}^{2}$ (typically found in empty plots between houses) were counted as 1 unit. Larger piles (typically found on the side of busy roads) were coded proportionally, therefore a garbage pile three times the size of a single unit was counted as 3 units. Finally, as with the other food sources, the number of garbage units in each sample area was tallied as can be seen in Table S2.

\section{Data analysis}

\section{Differences between neighbourhoods}

Two one-way ANOVAs were conducted to analyse the differences between mean population of free-ranging dogs as well as mean number of houses in neighbourhoods of different socio-economic classes. This was done with IBM SPSS Statistics 24 (IBM Corp. 2016) using the data collected.

\section{Estimating percentage of houses that feed strays}

Percentage of houses that feed strays was estimated using the following formula:

$$
\begin{aligned}
\text { \%housesthat feedstraydogs }= & \frac{\operatorname{dogs}}{\text { houses } \times \operatorname{dogs} \text { fedperhouse }} \\
& \times 100
\end{aligned}
$$

Number of dogs and number of houses were taken from the data collected per sampling unit, while the number of dogs fed per house was taken as 1.4. This number is based on figures produced by Morters et al. (2014). They found that in two villages in Johannesburg, South Africa as well as one in Bali, Indonesia, the average number of free-ranging dogs maintained by a single household was 1.3 , and 1.7 in another village in Bali, producing an average of 1.4 overall. Since the average was sufficiently consistent over these widely different geographic and cultural contexts, we used this figure in our calculation.

\section{Generalized linear model analysis}

Generalized linear models were constructed to analyse the weight of different food sources in predicting free-ranging dog populations. Since the response data had a count distribution which was overdispersed ( $\mu_{\text {of population }}=35.54, \sigma 2_{\text {of popu- }}$ lation =593.37), the GLMs were conducted in the form of negative binomial models with a log-link function. The analysis was performed in R 3.6.3 (R Core Development Team 2016). Model selection was carried out using the 'MuMIn' package (Bartoń 2016).

Prior to running the analysis, the predictor variables were re-scaled by centering in order to account for the differences in range of values across variables. Additionally, the predictor variables were checked for multicollinearity. The variable 'shops' was removed from the dataset since the VIF exceeded the threshold value (VIF = 7.677). The adjusted dataset has low multicollinearity $(\mathrm{VIF}<5)$.

\section{Model selection inference}

Six alternative hypotheses were constructed to explore potential relationships between various food sources and FRD populations. The hypotheses and the rationale behind them are detailed in Table 1. Model selection and inference was applied by using the Akaike Information Criteria $\mathrm{AIC}_{\mathrm{c}}$, corrected for small sample size $(n=28)$. Akaike weights were used to evaluate the relative likelihood of the models. McFadden pseudo $\mathrm{R}^{2}$ is also presented to show the improvement of each model from null models.

In order to assess the relative importance of predictors in the best models, the Sum of Weights approach outlined in Burnham and Anderson (2002) was used. The AIC weights of the models where the predictor was present were summed up. In order to use this method, the number of models containing each predictor must be equal, so one model was added to this step to balance the set. The details are presented in the results.

\section{Methods - Differences in people's attitudes}

\section{Data collection}

\section{Participants}

A sample of residents of northern Bangalore were surveyed about their attitudes towards free-ranging dogs. The interviews took place in two sessions determined by when the lead researcher was in the city. The first was in-between the 13th and 26th of August 2018, and included the online survey with 37 respondents, as well as 42 interviews on the street. The second was inbetween the 20th and 23rd of January 2019, and included 22 on-street interviews.

The participants were sampled from five socio-economic categories, namely Upper, Upper Middle, Middle, Lower Middle and Lower. Whereas in the ecological survey the categories were determined by the general socio-economic character of the neighbourhood, here respondents were assessed individually. The lead author subjectively assigned the categorisation based on a combination of questions regarding the job of the main earner of the family, neighbourhood, ownership of a car or two-wheeler and type of house. A more reliable method would be to obtain the income of the household but due to the sensitive nature of the question, and the 
Table 1 Hypothesised GLM models included in analysis including predictor values and explanation of each hypothesis

\begin{tabular}{llll}
\hline Hypothesis & Model & Predictors & Rationale \\
\hline H1 & Direct sources & Bakeries, Houses & Sources at which people directly feed dogs \\
H2 & Indirect sources & Butchers, Restaurants, Garbage & Sources at which food (waste) can be found by dogs \\
H3 & Commercial sources & Bakeries, Butchers, Restaurants & Concentrated largely in commercial areas or streets \\
H4 & Non-commercial sources & Garbage, Houses & Not restricted to commercial areas \\
H5 & Direct sources and garbage & Bakeries, Houses, Garbage & $\begin{array}{c}\text { Mixed group of direct and indirect sources to } \\
\text { investigate whether the population depends } \\
\end{array}$ \\
& & on a combination to survive \\
\hline
\end{tabular}

possibility that including it might have lowered the response rate or been answered untruthfully, the indirect method was used instead.

The upper-class respondents were mostly residents of a gated residential complex that the lead author grew up in. They were contacted by means of an email and answered the survey through Google Forms. The remaining respondents were recruited through convenience sampling in the street in various neighbourhoods that included or adjoined the areas where the dog surveys were conducted. The interviews were conducted in different localities to capture geographic variation in responses. Further, some respondents were residents and others were passing through to their places of work. They were verbally asked the questions and their answers were recorded in the Google Forms document by the interviewer. One limitation of this methodological disparity is that it could account for longer and more deliberate answers being given by the first set of respondents, since they could spend more time on it while those in the street typically did not talk for long. Additionally, the respondents on the street were mostly spoken with in Kannada, which was then translated into English.

\section{Survey}

The ethnographic research was conducted by way of a survey which produced both quantitative and qualitative data (Survey questions available in ESM 1). The items on the survey related to the categories (a) Demographics, (b) Socio-economic class, (c) Opinion about free-ranging dogs and (d) Contact with (free-ranging) dogs. The quantitatively analysable questions that were used in the results were:

(a) To what extent do you agree with the following statement: There is a stray dog menace that needs to be solved by the city administration. 1-5 Likert scale from 'Disagree strongly' to 'Agree strongly'.

(b) Do you think stray dogs should be removed from our cities? (a) Yes (b) No (c) Maybe (d) Other.

(c) Do you feed stray dogs? (a) Yes (b) No (c) No, but I support those who do.
In addition, there were three opportunities for respondents to elaborate, which generated qualitative data that was used to explain the quantitative trends produced.

\section{Data curation}

In order to analyse the results quantitatively, the responses to two questions needed to be recoded. First, the replies to the question 'Do you think stray dogs should be removed from our cities? (a) Yes (b) No (c) Maybe (d) Other', were recoded as $\mathrm{Yes}=1$, Maybe $=0.5, \mathrm{No}=0$.

For respondents who did not give a clear 'yes' or 'no' answer, their answers were recoded into 'yes' or 'no' based on their longer opinion answers. Those with responses akin to, 'we should not remove them all, but we should have fewer' or 'we should find a way to coexist' or 'only remove some - the dangerous ones' - were recoded into 'no'. Those whose other answers gave no further indication of how they felt, and one that essentially said, 'they cannot be removed because of the impracticalities of current solutions' was recoded as 'maybe'. One that said dogs should be "removed from slums and areas where they are uncared for ... should be tagged and only be kept in communities where individuals are willing to take responsibility to ensure they do not allow them to reproduce uncared (for) litters" was recoded as 'yes'.

Second, for the question 'Do you feed stray dogs? (a) Yes (b) No (c) No, but I support those who do' the answers were recoded as 'Yes $=1$, No $=0$ '. The response 'No but I support those who do' was discounted since it is not informative of behaviour.

\section{Data analysis}

\section{Quantitative analysis}

The quantitative trends in responses were illustrated through a means plot and percentage-wise distributions of answers across socio-economic classes, to the three questions above. The figures were produced using the 'ggplot2' package (Wickham 2016) in R 3.6.3 (R Core Development Team 2016). 


\section{Qualitative analysis}

The qualitative analysis was performed on opinions expressed by survey respondents at three points in the survey. Views that were expressed repeatedly were highlighted and the number of times they were expressed by people from each class was assessed. These views were then categorised into three broad categories: 'closeness', 'ethical reflection', and 'change and responsibility'. In this paper, 'closeness' refers to the physical closeness of respondents to free-ranging dogs as a result of frequent daily encounters with them, and the possible effects of this on attitudes. 'Ethical reflection' looks at ethical points that were raised by respondents, about how free-ranging dogs 'should' or 'must' be treated, and how that influenced the interventions individuals suggested. 'Change and responsibility' deals with how respondents approached the possibility and practicality of interventions, as well as to whom they allocated the responsibility of managing FRD populations. This semiqualitative coding scheme was then drawn into an analysis that was used to explain the quantitative trends observed.

\section{Results - Ecology of free-ranging dogs}

\section{Dog population statistics}

The population of free-ranging dogs ranged from 192 to 1888 per square kilometre across the units sampled. The distribution of dogs was related to socio-economic class, with the lowest dog population found in the upper class neighbourhoods, with higher numbers in the middle, and highest in the lower-class areas (Table 2). As can be expected, there is a corresponding increase in human population between the classes of neighbourhoods, as seen through the number of houses (Table 3). There was a statistically significant difference across neighbourhoods with different socio-economic classes in the mean population of $\operatorname{dogs}(\mathrm{F}=9.52, p=0.001)$ as well as the mean number of houses ( $\mathrm{F}=6.96, p=0.005)$, as determined by conducting one-way ANOVAs (Table S6).

\section{Percentage of houses that feed free-ranging dogs}

The average percentage of houses feeding free-ranging dogs was found to be highest in the lower-class

Table 2 Mean population of FRD per neighbourhood type

\begin{tabular}{llll}
\hline Neighbourhood Type & $\mathrm{n}$ & Mean \# Dogs & Std. Deviation \\
\hline Lower class & 9 & 57.4 & 27.42 \\
Middle class & 6 & 39.8 & 15.55 \\
Upper class & 8 & 17.0 & 3.07 \\
\hline
\end{tabular}

Table 3 Mean number of houses per neighbourhood type

\begin{tabular}{llll}
\hline Neighbourhood Type & $\mathrm{n}$ & Mean \# Houses & Std. Deviation \\
\hline Lower class & 9 & 233 & 84.82 \\
Middle class & 6 & 176 & 43.48 \\
Upper class & 8 & 123 & 32.64 \\
\hline
\end{tabular}

neighbourhoods, followed by the middle, and finally the upper-class areas (Fig. 1). This difference between classes was found to be significant through a one-way ANOVA $(\mathrm{F}=6.76, p=0.006)$ (Table S6).

\section{Generalized linear model (GLM) analysis with multi- model inference}

The results of comparing six hypothesised GLMs by multimodel inference are presented below.

\section{Model selection and inference}

The best models were 'direct sources and garbage', and 'direct sources', as shown in Table 4. The model 'non-commercial sources' was also ranked well (Table 4). The remaining two models 'indirect sources' and 'commercial sources' had relatively little support in comparison $(\triangle \mathrm{AICc}>10)$.

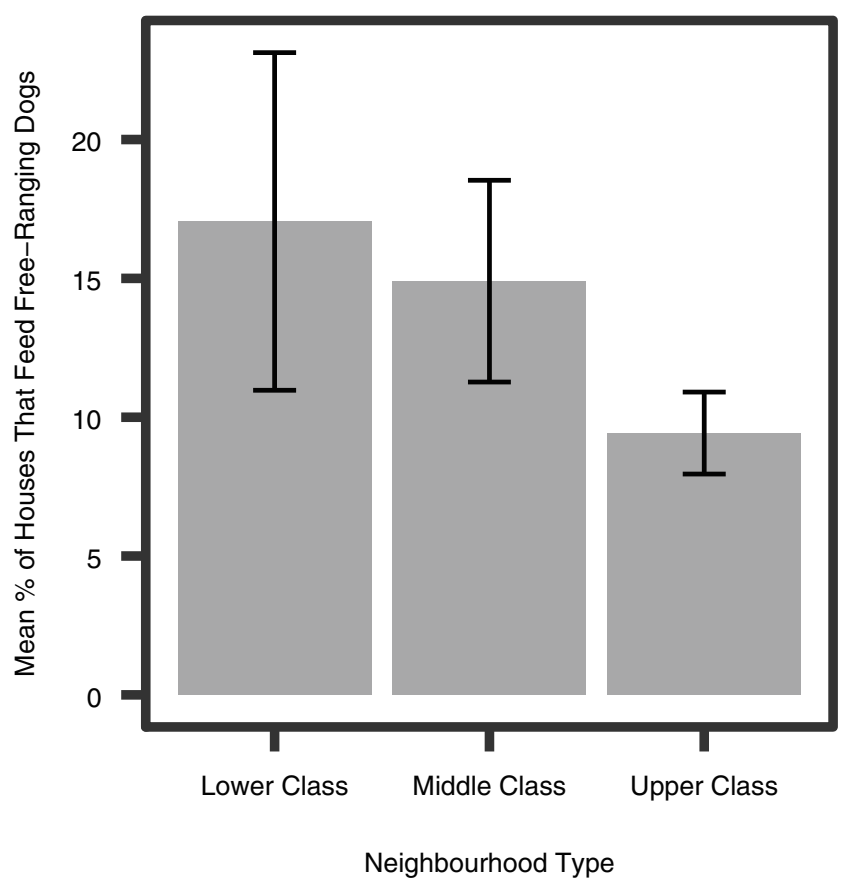

Fig. 1 Means plot of $\%$ of houses that feed free-ranging dogs per neighbourhood type $(n=23)$ 
Table 4 Results of model selection and multimodel inference as well as McFadden's pseudo $\mathrm{R}^{2}$

\begin{tabular}{|c|c|c|c|c|c|c|c|c|}
\hline Hypothesis\# & Model & Predictors & $\begin{array}{l}\text { \#of Model } \\
\text { Parameters }\end{array}$ & $\begin{array}{l}\text { Log- } \\
\text { Likelihood }\end{array}$ & $\mathrm{AICc}$ & $\Delta \mathrm{AICc}$ & Weights & $\begin{array}{l}\text { McFadden's } \\
\text { pseudo } \mathrm{R}^{2}\end{array}$ \\
\hline H5 & Direct sources and garbage & Bakeries, Houses, Garbage & 5 & -106.471 & 225.7 & 0.00 & 0.612 & 0.126 \\
\hline $\mathrm{H} 1$ & Direct sources & Bakeries, Houses & 4 & -108.804 & 227.3 & 1.68 & 0.265 & 0.107 \\
\hline H4 & Non-commercial sources & Garbage, Houses & 4 & -109.589 & 228.9 & 3.25 & 0.121 & 0.101 \\
\hline $\mathrm{H} 3$ & Commercial sources & Bakeries, Butchers, Restaurants & 5 & -113.968 & 237.7 & 12.01 & 0.002 & 0.065 \\
\hline $\mathrm{H} 2$ & Indirect sources & Butchers, Restaurants, Garbage & 5 & -114.548 & 2438.8 & 13.17 & 0.001 & 0.060 \\
\hline
\end{tabular}

\section{Parameter estimates for best models}

The best model (H5,) contains a mixture of direct and indirect sources, and the second best model H1 comprises only direct sources. The parameter estimates and associated statistics for the best models are presented below (Table 5 and Table 6 ).

From our best model we see that bakeries $(p=0.0076)$, houses $(p=0.0004)$ and garbage piles $(p=0.0279)$ are all significant predictors of free-ranging dog populations. In order to compare the relative weights of the three predictors, the best models were re-run, with the addition of a model containing bakeries and garbage to balance the set by ensuring that all the predictors were in an equal number of models (Table 7). The sum of weights for each predictor were then compared, showing that the houses were followed by bakeries and then garbage in importance (Table 8).

\section{Results - Differences in people's attitudes}

A total of 100 individuals were interviewed for the ethnographic section of the paper, with 97 viable responses recorded. However, the sample size differs slightly per analysis because of missing responses on certain variables resulting in 84-97 responses per question. Of the 97 respondents there was almost an equal number of men (48) and women (49) (Table S3), and most were middle-aged, specifically 35-44 (17), 45-54 (33) and 55-64 (20) years of age (Table S4). Respondents were surveyed from across socio-economic classes, specifically Upper (40), Upper Middle (12), Middle (16), Lower Middle (9) and Lower (20) (Table S5). Due to the lack of an equal number of respondents across the SE classes and

Table 5 Parameter estimates, standard errors and Z-values of the highest-ranked model 'Direct sources and garbage'

\begin{tabular}{llllll}
\hline Parameter & df & Estimate & Std. Error & Z value & $\operatorname{Pr}(>|\mathrm{z}|)$ \\
\hline Intercept & 27 & 3.449 & 0.067 & 51.658 & $<2 \mathrm{e}-16$ \\
Bakeries & 27 & 0.194 & 0.073 & 2.670 & 0.0076 \\
Houses & 27 & 0.276 & 0.079 & 3.515 & 0.0004 \\
Garbage & 27 & 0.147 & 0.067 & 2.198 & 0.0279 \\
\hline
\end{tabular}

the over-representation of the "upper SE-classes", caution is advised in interpreting the results.

\section{Quantitative analysis}

The quantitative analysis of the survey responses produced certain trends in attitudes towards dogs. The upper class on the whole viewed free-ranging dogs more as a menace than the lower class, as seen in their response to the statement 'There is a stray dog menace that needs to be solved by the city administration' (Fig. 2). Unexpectedly, the averages from the intermittent classes display a contrasting trend, as the upper middle classes viewed dogs less as a menace than middle and lower middle, which will be discussed further in the qualitative analysis.

The second question 'Do you think stray dogs should be removed from our cities' was asked to assess the severity of opinions and how respondents viewed interventions (Fig. 3). Over half of the individuals surveyed from each SE class responded 'yes' When contrasted with the responses to the previous question, this reveals a difference between how individuals from the lower and upper class perceive free-ranging dogs in general and their attitudes towards interventions, which is discussed further below.

Third, in order to investigate behavioural differences among the groups, we assessed what percentage of each class of respondents feeds free-ranging dogs. Figure 4 shows that high percentages of all the classes, except the upper-class, feed dogs. This difference could be explained by the fact that most of the upper-class respondents were residents of a gated colony, who would have to make the

Table 6 Parameter estimates, standard errors and Z-values of the second best model 'Direct sources'

\begin{tabular}{llllll}
\hline Parameter & df & Estimate & Std. Error & Z value & $\operatorname{Pr}(>|\mathrm{z}|)$ \\
\hline Intercept & 27 & 3.460 & 0.073 & 47.486 & $<2 \mathrm{e}-16$ \\
Bakeries & 27 & 0.173 & 0.081 & 2.150 & 0.0316 \\
Houses & 27 & 0.326 & 0.084 & 3.891 & 0.0001 \\
\hline
\end{tabular}


Table 7 Results of multimodel selection used to determine the relative importance of predictors

\begin{tabular}{|c|c|c|c|c|c|c|}
\hline \# & Model & Predictors & $\begin{array}{l}\text { Log- } \\
\text { Likelihood }\end{array}$ & $\mathrm{AICc}$ & $\Delta \mathrm{AICc}$ & Weights \\
\hline H5 & Direct sources and garbage & Bakeries, Houses, Garbage & -106.471 & 225.7 & 0.00 & 0.603 \\
\hline H1 & Direct sources & Bakeries, Houses & -108.804 & 227.3 & 1.68 & 0.261 \\
\hline $\mathrm{H} 4$ & Non-commercial sources & Garbage, Houses & -109.589 & 228.9 & 3.25 & 0.119 \\
\hline - & Additional model with garbage and bakeries & Bakeries, Garbage & -111.517 & 232.8 & 7.10 & 0.017 \\
\hline
\end{tabular}

effort of travelling outside their compound to find dogs to feed.

Finally, we collected data on whether respondents 'currently have or have previously had pet dogs at home', to explore the effects of pet ownership on attitudes towards FRDs (Table 9). Overall having or having had a pet dog elicited the responses 'stray dogs should be removed' and 'stray dogs should not be removed' to an almost equal extent. This is particularly relevant in the upper class which had the highest sample size and are most likely to keep pet dogs. Amongst those who did not at present or in the past have a pet dog, most said 'stray dogs should be removed' in most classes.

\section{Qualitative analysis}

The qualitative data obtained in the surveys is analysed in the following section and used to explain the results presented above. The findings are categorised into three themes that can be used to understand the differences in individuals' opinions on free-ranging dogs. These themes are 'closeness', 'ethical reflection' and 'change and responsibility'. The first of these describes differences that are associated with the physical 'closeness' between individuals and dogs, which is determined predominantly by where individuals live. The second and third themes explore differences that fall along socioeconomic class lines.

Closeness Attitudes towards free-ranging dogs appeared to be strongly related to the physical closeness of the individual to the dogs. Closeness here is conceptualised as frequent daily contact between individuals and these dogs, as a result of living in close physical proximity to them. This was seen amongst individuals who lived in independent houses that

Table 8 Sum of Weights for predictor variables and their relative importance

\begin{tabular}{lll}
\hline Predictor & Sum of Weights & Importance rank \\
\hline Houses & 0.983 & I \\
Bakeries & 0.881 & II \\
Garbage & 0.739 & III \\
\hline
\end{tabular}

opened onto public streets, rather than those who lived in apartment buildings or gated colonies, who would not encounter free-ranging dogs in their immediate living environment. Importantly, this was not entirely determined by socio-economic class differences. In this sample, the upperclass respondents were largely from a gated colony, but most of the surveyed individuals from other classes lived in independent houses. In a broader sample, we would encounter a better mix of socio-economic classes and closeness across respondents.

We explain the association with closeness as the less overall contact a person has with free-ranging dogs, the less positive contact they have with the dogs and thereby, the more negative their views towards dogs, and vice versa. For people with low closeness, the contact or information that they would have about these dogs would tend to come from a combination of transitional encounters with them - while travelling through streets they inhabit - and news reports. The former is often

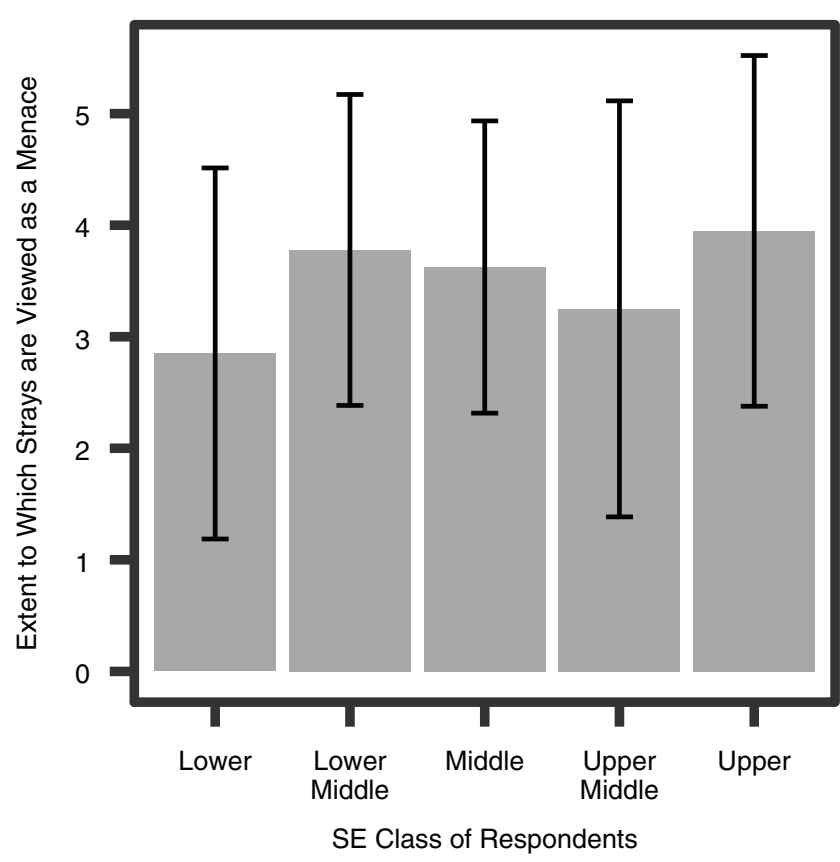

Fig. 2 Means plot of extent to which respondents from different classes regard stray dogs as a menace to be solved by the city administration, on Likert scale from 1 to $5(n=95, M=3.56, S D=1.60)$. The standard deviation of each mean is represented as error bars 


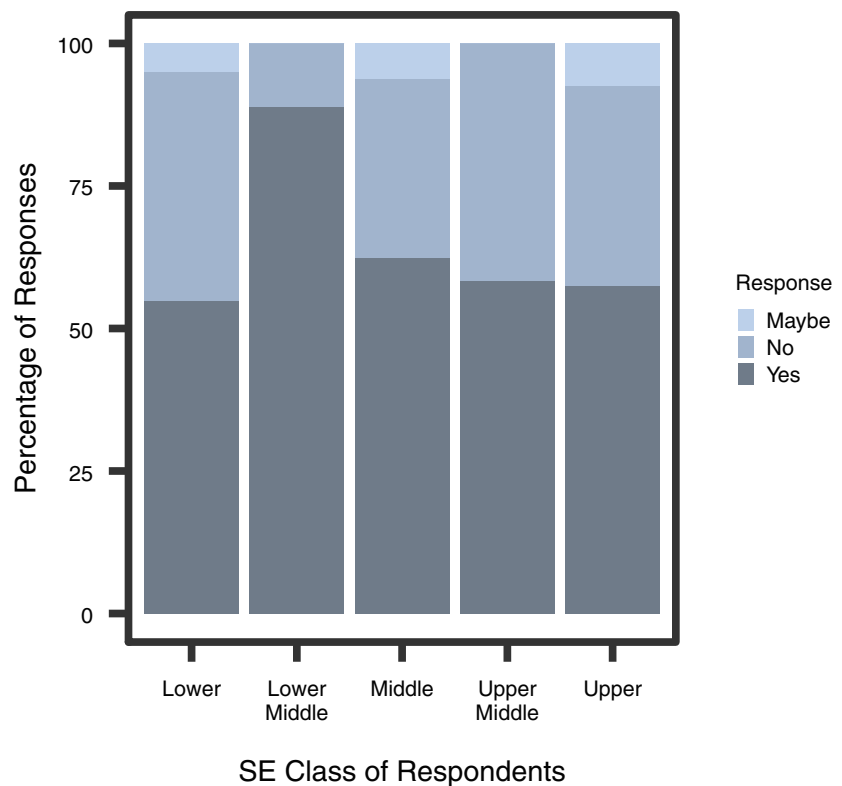

Fig. 3 Percentage of respondents from each SE class who responded with 'yes', 'maybe' and 'no' to whether 'free-ranging dogs should be removed from Indian cities' $(n=97)$

negative as the dogs chase individuals and vehicles that pass through their territory. The latter is also usually not just negative, but drastically negative, as it offers a one-sided narrative constructed around deaths and dog bites. Particularly in recent years, the reporting on dog attacks has intensified. This could cause such individuals to develop an abstract and skewed perception of the animals. They are conceptualised by this group as a "dangerous nuisance" that "needs to be controlled".

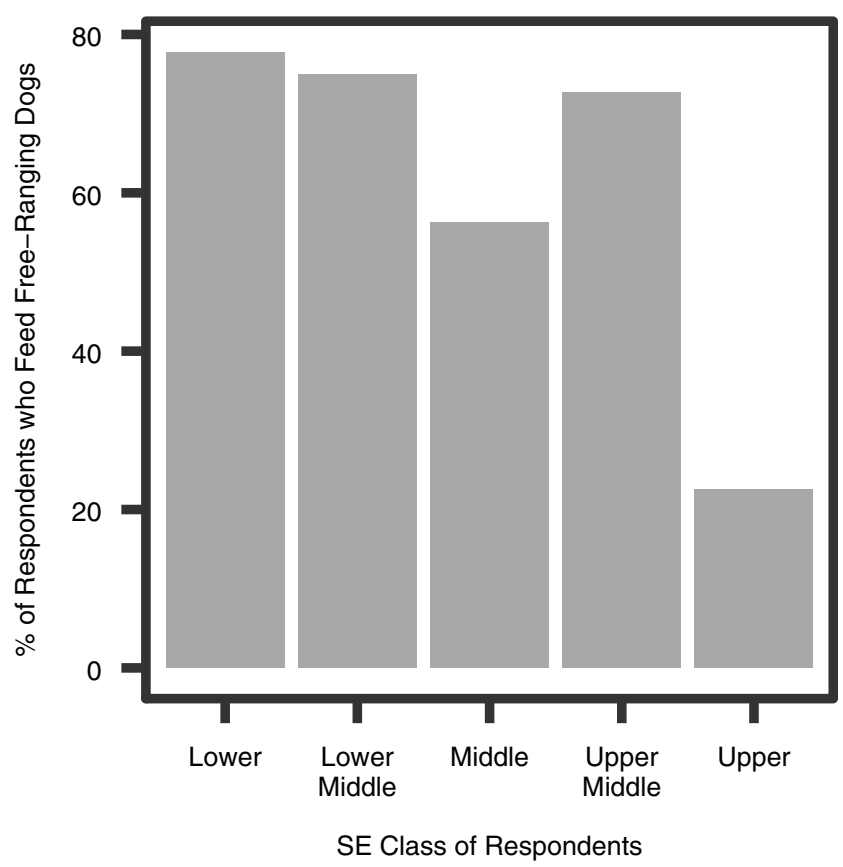

Fig. 4 Percentage of respondents from different classes who report feeding free-ranging dogs $(n=84, M=52.2, S D=48)$
On the contrary, people who live in independent houses that encounter dogs on their doorstep have more contact with them. They are seen as companions, in addition to noisemakers and car-chasers. In other words, they are not necessarily viewed as a problem but a daily feature of these individuals' lives and therefore such individuals have more of a nuanced view and refer to specific dogs rather than the collective. As explained by one respondent: "There are some that don't bother you and some that can get quite aggressive" (upper-class female, 22 y.o.). This would explain why such individuals often proposed that certain "dangerous" or "mad" individual dogs be removed, rather than all of them, a distinction that people from the gated colony do not make.

One important difference in views towards free-ranging dogs unexpectedly was not related to closeness but rather to socio-economic class lines. The upper and upper middle classes viewed the dogs more in terms of the danger they pose, citing dogs' propensity to 'attack' far more than those from the lower classes, while the latter also appreciated their 'protective' behaviour: "If they are a menace elsewhere they should be removed but here there's no problem. They act as our guards" (lower-middle female, 35-44 y.o.). This aspect is important in framing suggestions for policy because it reflects the vulnerability felt by the lower classes towards burglars that free-ranging dogs help to mitigate. This will be further discussed later in the paper.

Ethical reflection We see an interesting result in comparing Figs. 2 and 3. The figures show that for many of the upperclass respondents there is a disconnect between regarding free-ranging dogs as a menace, and wanting them to be removed from the city. Relative to the lower class, on average the upper class was far more likely to consider the dogs to be a menace. However simultaneously, the percentage of respondents from the upper (58\%) class who thought 'stray dogs should be removed from our cities' is very similar to that of the lower (55\%) class. And of those from the upper class who did not think the dogs should be removed, nearly half (43\%) did consider them a menace (Likert scale 4 or 5). This unwillingness to remove dogs can be explained in terms of how individuals think about animal welfare issues. It appears that persons from the higher socio-economic classes think about dogs more on 'ethical' and 'humane' grounds. Many are seen to think on the lines of "Any option we choose, we must avoid cruelty to every living being - including Dogs" (upper-class male, 65-74 y.o). On one extreme there is the 'animal welfarist' category of individuals who are against removal because they equate a human's life to a dog's life and believe that both species have a right to the planet. For instance, one respondent said, "We need to learn to live in harmony with the beings we share the planet with. If there are people out there who think they need to "exterminate" strays or another species for that matter, then their thinking is no different from that of religious terrorists who in the name of "cleansing" take innocent lives" 
Table 9 Relation between having/having had a pet dog and opinion on removing free-ranging dogs, by class

\begin{tabular}{llllll}
\hline Class & $\mathrm{n}$ & Have pet/remove & $\begin{array}{l}\text { Have pet/Don't } \\
\text { remove }\end{array}$ & No pet/remove & $\begin{array}{l}\text { No pet/Don't } \\
\text { remove }\end{array}$ \\
\hline Upper & 36 & 9 & 12 & 12 & 3 \\
Upper Middle & 11 & 1 & 1 & 5 & 4 \\
Middle & 15 & 2 & 1 & 9 & 3 \\
Lower Middle & 7 & 1 & 1 & 4 & 1 \\
Lower & 16 & 2 & 0 & 5 & 9 \\
\hline
\end{tabular}

(upper-class female, 18-24 y.o.). Another similarly said, "We need (to) handle this issue the way we are handling stray human beings. In fact [the dogs] pollute less, as far as our environment is concerned" (upper-class male, 65-74 y.o.). On the other end of the spectrum, there was one individual who said that mass culling humanely would be beneficial to both species since the dogs lead a hard life. In-between are respondents we call 'transporters' who suggested that freeranging dogs should be removed from the cities and kept on a farm somewhere because they do not want to kill the dogs: "They should be moved elsewhere. I can't recommend that they are killed, and the $\mathrm{ABC}$ isn't working, the numbers only increase" (upper middle-class male, 65-74 y.o.). Then we identified the 'impractical' who suggested that the $\mathrm{ABC}$ programme is the humane option and simply needs to be implemented effectively: "Bbmp (Bangalore's civic administrative body) should have sterilized dogs many years back, unfortunately they only did it partially. This is the scientific way of managing stray dogs" (upper-class male, 45-54 y.o.). Finally, there were the 'practical sceptics' who would wish the dogs to be removed but recognise that there is no viable strategy to do so at the moment: "They cannot be removed as the population is high and the solution inhuman. But there needs to be a comprehensive discussion on practices worldwide and solutions" (upper-class female, $45-54$ y.o.).

Moving from the upper to the lower-class responses we saw almost no responses in the 'animal welfarist' category, showing that it is a type of thinking predominantly unique to the upper class. Additionally, the humane angle was decreasingly brought up, with a concurrent increase in 'eradicator' thinking - i.e., "If they're left alone, they'll bite everyone... It's better if they're taken at once" (lower middle-class female, 25-34 y.o.). There was an increase in respondents opting for immediate removal because "dogs bite" or even simply because "they are a nuisance." However, at the same time, in the lower class, there were also a number of respondents who considered free-ranging dogs 'harmless' and even 'helpful' because they "keep burglars out", a consideration largely missing among the upper-class respondents.

This consideration or lack thereof of 'what is ethical' can be seen clearly in the types of solutions proposed. Among the upper classes, there was a clear preference for 'humane' methods of removal such as the $\mathrm{ABC}$ program, while among the lower classes, for those who did want removal, there was a preference for quick methods such as mass culling. In Table 10 we show the proportion of individuals who preferred the $\mathrm{ABC}$ program to those who preferred mass culling, amongst those who opted for 'Yes they should be removed'. Those who suggested other methods or a mix of methods have not been included in this comparison.

Change and responsibility Besides the differences in ethical reflections, individuals from different socio-economic classes also tended to display variations in how they discussed the subject of interventions. For instance, respondents from the middle, lower middle and lower classes were less proclamatory in their proposed solutions than the upper classes: "If they can go, that will be good" (lower middle-class male, $65-74$ y.o.). In the conversation it became clear to the interviewer that effective interventions were out of the former's range of expectations. Therefore, solutions proposed were clearly spoken of in hypothetical terms or with scepticism, such as "If they could all be removed at once that would be great" (lower-class female, 5564 y.o. \& middle-class female, $45-54$ y.o. \& others). However, from context it was apparent that they were used to adjusting to conditions and had little faith that anything would truly change.

In contrast, the upper- and upper middle-class respondents proposed solutions with more self-assurance and vehemence in their beliefs, phrasing their responses along the lines of "something must be done". It would appear that the upper classes felt less bound by the inefficiency of the administration in envisioning interventions. This could be because they are more insulated from the inefficiency on a daily basis, while the lower classes encounter it more, for instance in having to

Table 10 Preference for FRD removal by ABC or Mass culling, by class

\begin{tabular}{llllll}
\hline & Upper & Upper middle & Middle & Middle lower & Lower \\
\hline ABC & 10 & 6 & 4 & 0 & 2 \\
Mass culling & 1 & 0 & 5 & 5 & 5 \\
Total Yes & 22 & 7 & 12 & 5 & 9 \\
ABC $\%$ & 45.5 & 85.7 & 33.3 & 0.0 & 22.2 \\
Culling\% & 4.5 & 0.0 & 41.7 & 100.0 & 55.6 \\
\hline
\end{tabular}

a Total who opted for 'Yes they should be removed' 
Table 11 Intersection of feeding behaviour and opinion on removing free-ranging dogs, by class

\begin{tabular}{llllll}
\hline Class & $\mathrm{n}$ & $\begin{array}{l}\text { Don't } \\
\text { feed/Remove }\end{array}$ & $\begin{array}{l}\text { Feed/ } \\
\text { Remove }\end{array}$ & $\begin{array}{l}\text { Feed/Don't } \\
\text { remove }\end{array}$ & $\begin{array}{l}\text { Don't feed/don't } \\
\text { remove }\end{array}$ \\
\hline Upper & 26 & 19 & 0 & 5 & 2 \\
Upper Middle & 11 & 3 & 4 & 4 & 0 \\
Middle & 14 & 6 & 6 & 2 & 0 \\
$\begin{array}{l}\text { Lower } \\
\quad \text { Middle }\end{array}$ & 6 & 2 & 2 & 2 & 0 \\
$\begin{array}{l}\text { Lower } \\
\text { Unem }\end{array}$ & 19 & 3 & 6 & 9 & 1 \\
\hline
\end{tabular}

deal with a regular shortage of water. Even the 'practical sceptics' group among the upper class which proposed that there was no feasible solution yet, often suggested a multi-pronged approach, maintaining that the dogs "need to be controlled".

This also suggests a higher feeling of human responsibility for the situation amongst the upper classes who tended to view dogs as 'for us to take care of', while the lower classes might view them more as a part of the natural environment: "If you trouble them, they trouble you. If you leave them alone, they leave you alone. Why do anything to them?" (lower-class female, 45-54 y.o.). Further, there was also a variation in the assignment of responsibility. All the classes place responsibility for the intervention on the civil administration (BBMP), however in the upper, upper middle and middle classes, there was also mention of how citizens can contribute to the solution by not feeding or abandoning dogs. In contrast, there was a greater lack of perceived personal responsibility in dog population management from the lower classes, probably as a result of the closeness to dogs. This is particularly well illustrated by their feeding behaviour towards the dogs. Presented in Table 11 we can see that there was a disconnect between feeding free-ranging dogs and thinking that they should be removed, in the classes living closer to the animals. Although some respondents in the upper middle and middle classes displayed perceived personal responsibility in their responses, others displayed the same disconnect as the lower classes. Personal responsibility thus appears to be a feature of classes that is moderated by closeness to dogs.

\section{Discussion}

In this study, we have identified the food sources that substantially support the free-ranging dog population of North Bangalore. Additionally, we have extracted trends in attitudes of the residents from across socio-economic classes of the area. These results together allow us to propose an alternative approach to managing free-ranging dog populations in Bangalore by targeting the carrying capacity of the urban environment instead of the dog population directly.

We found that of the food sources surveyed, a mixture of direct sources and indirect sources significantly support the free-ranging dog population in Bangalore. Namely: houses, bakeries and garbage piles, in that order of relative importance. The foremost importance of houses confirms the findings by several authors (Butler and Bingham 2000; Gompper, 2014), who likewise found that dog population density increases with an increase in human population. It also lends support to research that has found that free-ranging dogs in urban settings are supported primarily by referral households which engage in direct feeding of the animals (Morters et al. 2014). We found that the estimated percentage of households that feed these dogs is relatively small at $10 \%$ in upper-, $16 \%$ middle- and $18 \%$ in lower-class units, compared to 42 and $73 \%$ in two Indonesian villages (Morters et al. 2014). It is thus evident that a small proportion of houses can sustain large free-ranging dog populations.

The finding that garbage sources, although significant, are weaker predictors of populations goes against research by Butler and Bingham (2000) as well as Reese (2005) who suggested that in India, human waste food and faeces contribute highly to dog populations. We suggest that garbage serves as a secondary food source to household-maintained dogs (semi-owned free-ranging dogs) and as the primary food source to the population that is not linked to specific households. During the data collection, we noticed that large garbage piles were not very common, contrary to popular opinion. Many neighbourhoods, particularly dense ones found in lower socio-economic areas did not have garbage piles in the narrow streets and the door-to-door garbage collection system appeared to be regular and well-used. Garbage piles were only seen on large roads, main shopping streets and in vacant lots present in middle- and upper-class neighbourhoods.

In terms of the differences in attitudes towards free-ranging dogs between socio-economic groups, we found that while class differences remain a prominent variable in understanding views, it appears that closeness to dogs was also an important factor. The responses of the upper middle class are a good way to identify what can be ascribed to the closeness variable and what is a feature of perspective based on rearing. Whereas closeness to dogs explains whether they are seen on a nuanced individual basis or considered a menace on a population-level, socio-economic divisions appear to play a role in explaining differences in how free-ranging dogs are viewed in 
three ways: a. upper classes are likely to pay more attention to the ethical side of interventions than the lower classes, which were more likely to opt for quick methods of population removal; b. there is a greater belief in the plausibility of change, and the assertiveness with which interventions are suggested by the upper classes than the lower classes; $c$. the lower classes tend to feel less personal responsibility towards dog population management, in spite of (or perhaps because of) often living in closer proximity to them. On the other hand they do attach a value to individual dogs for the guard function they provide.

Nonetheless, although opinions differed widely across groups in the sample, there was a net recognition that freeranging dogs pose an issue and require better management. Since there was no consensus on removing them from the city entirely, we propose reducing the carrying capacity of the environment and thereby the free-ranging dog population long-term. After all, even if the $\mathrm{ABC}$ programme were to be implemented more effectively, as long as the same amount of food sources are available, dogs from surrounding areas would enter the urban environment. Ultimately, reducing the population would allow the lower socio-economic classes to retain the protection of the dogs while reducing the 'nuisance' that they cause. In order to do so, we make two policy suggestions. First, in order to reduce the carrying capacity of the environment and thereby the long-term free-ranging dog population, we suggest regulating the feeding of dogs around bakeries and implementing proper waste management in public spaces. Second, we advise that by increasing awareness about the role that the household plays in sustaining a population, we can increase individuals' feeling of personal responsibility in controlling the population, particularly amongst the lower classes, but generally in those who live close to the dogs. Since even the group that feels protected by the dogs often said that they would prefer fewer numbers, this awareness could also be useful in these neighbourhoods. While Herbert et al. (2012) suggested that households can be made aware of the role they can play by not dumping waste, we propose that more important is the awareness of the impact of feeding the dogs directly. An increased feeling of personal responsibility for semi-owned free-ranging dogs might also contribute to sterilisation and immunisation coverage.

The value of the results and policy suggestions in this study can be verified by future interventional research that quantifies the impact on the population by reducing the environmental carrying capacity in the manner proposed here. Future planning would also be aided by gathering data on the ratio of owned to unowned free-ranging dogs in the Indian setting, as well as surveying the actual proportion of houses that feeds them. Additionally, since the study was conducted at the outskirts of the city, a survey area in the centre of the city is suggested to test the proposed theories. Likewise, the empirical evidence for the closeness hypothesis could be strengthened by surveying respondents from a mix of different housing types and socio-economic groups.

\section{Conclusion}

This paper looked at the impact of different food sources on dog populations as well as the dynamic between free-ranging dogs and humans from different socio-economic classes. We found that houses, bakeries and garbage piles were significant predictors of dog population sizes, and that there was a strong difference between dog populations in high and low socio-economic neighbourhoods. Crucially, it was found that a small number of houses can support a large population of free-ranging dogs, while trash piles serve a secondary role in comparison. Across classes, opinions towards the animals differed quite widely but over half the respondents from each class felt free-ranging dogs should be removed from cities and the net opinion appeared to be that at the least, the free-ranging dog population needs to be controlled. Thus, we suggest that the city administration take steps to reduce the carrying capacity of the environment by regulating feeding around bakeries and improving waste management in public spaces. Creating awareness about the impact that household feeding has on the dog population could additionally help to control the population.

Supplementary Information The online version contains supplementary material available at https://doi.org/10.1007/s11252-021-01097-4.

Acknowledgments The authors are grateful to Nachiket Kelkar and Abhijit Kumar for their helpful inputs to the paper.

Author contributions All authors contributed to the study conception and design. Material preparation, data collection and analysis were performed by Shireen J Bhalla and supervised by Roy Kemmers, Abi T Vanak and Ana Vasques. The first draft of the manuscript was written by Shireen J Bhalla and all authors commented on previous versions of the manuscript. All authors read and approved the final manuscript.

Funding This study was supported in part by a DBT/Wellcome Trust India Alliance grant to ATV (Grant number: IA/CPHI/15/1/502028).

Compliance with ethical standards Informed consent: Informed consent was obtained from all individual participants included in the study.

Ethics approval for the dog population survey was not sought since the survey method was photographic capture-recapture from a distance, involving no direct interaction with the animals.

Conflict of interest The authors declare that they have no conflict of interest.

Open Access This article is licensed under a Creative Commons Attribution 4.0 International License, which permits use, sharing, adaptation, distribution and reproduction in any medium or format, as long as you give appropriate credit to the original author(s) and the source, provide a link to the Creative Commons licence, and indicate if changes were made. The images or other third party material in this article 
are included in the article's Creative Commons licence, unless indicated otherwise in a credit line to the material. If material is not included in the article's Creative Commons licence and your intended use is not permitted by statutory regulation or exceeds the permitted use, you will need to obtain permission directly from the copyright holder. To view a copy of this licence, visit http://creativecommons.org/licenses/by/4.0/.

\section{References}

Animal Welfare Board of India (2001) Animal Birth Control (Dogs) Rules, 2001. http://www.awbi.in/policy_acts_rules.html. Accessed 8 January 2019

Baquero OS, Akamine LA, Amaku M, Ferreira F (2016) Defining priorities for dog population management through mathematical modelling. Preventive Veterinary Medicine 123:121-127. https://doi.org/ 10.1016/j.prevetmed.2015.11.009

Bartoń K (2016) MuMIn: multi-model inference. R package version 1(43):17 https://cran.r-project.org/web/packages/MuMIn/index. html

Beck AM (1973) The ecology of stray dogs: a study of free-ranging urban animals. Purdue University Press, West Lafayette

Belsare AV, Gompper ME (2013) Assessing demographic and epidemiologic parameters of rural dog populations in India during mass vaccination campaigns. Preventive Veterinary Medicine 111:139 146. https://doi.org/10.1016/j.prevetmed.2013.04.003

Belsare A, Vanak AT (2020) Modelling the challenges of managing freeranging dog populations. Sci Rep 10:18874. https://doi.org/10.1038/ s41598-020-75828-6

Burnham KP, Anderson DR (2002) Model selection and multimodel inference: a practical information theoretic approach, 2nd edn. Springer, New York

Butler JRA, Bingham J (2000) Demography and dog-human relationships of the dog population in Zimbabwean communal lands. Vet Rec 147:442-446. https://doi.org/10.1136/vr.147.16.442

Chao A, Colwell RK, Chiu CH, Townsend D (2017) Seen once or more than once: applying good-Turing theory to estimate species richness using only unique observations and a species list. Methods Ecol Evol 8:1221-1232. https://doi.org/10.1111/2041-210X.12768

Chatterjee P (2009) India's ongoing war against rabies. Bull World Health Organ https://www.who.int/bulletin/volumes/87/12/09 021209/en/. Accessed 4 January 2019

Cliquet F, Gurbuxani J, Pradhan H et al (2007) The safety and efficacy of the oral rabies vaccine SAG2 in Indian stray dogs. Vaccine 25: 3409-3418. https://doi.org/10.1016/j.vaccine.2006.12.054

Coleman PG, Dye C (1996) Immunization coverage required to prevent outbreaks of dog rabies. Vaccine 14:185-186. https://doi.org/10. 1016/0264-410X(95)00197-9

Gompper ME (2014) The dog-human-wildlife interface: assessing the scope of the problem. In: Gompper ME (ed) Free-ranging dogs and wildlife conservation, 1st edn. Oxford University Press, New York, pp 9-54

Hampson K, Coudeville L, Lembo T, Sambo M, Kieffer A, Attlan M, Barrat J, Blanton JD, Briggs DJ, Cleaveland S, Costa P, Freuling CM, Hiby E, Knopf L, Leanes F, Meslin FX, Metlin A, Miranda ME, Müller T, Nel LH, Recuenco S, Rupprecht CE, Schumacher C, Taylor L, Vigilato MAN, Zinsstag J, Dushoff J, on behalf of the Global Alliance for Rabies Control Partners for Rabies Prevention (2015) Estimating the global burden of endemic canine rabies. PLoS Negl Trop Dis 9:e0003709. https://doi.org/10.1371/journal.pntd. 0003709
Herbert M, Basha R, Thangaraj S (2012) Community perception regarding rabies prevention and stray dog control in urban slums in India. Journal of Infection and Public Health 5:374-380. https://doi.org/ 10.1016/j.jiph.2012.05.002

IBM Corp. (2016) IBM SPSS statistics for windows, version 24.0. Armonk, NY, USA. www.ibm.com

Karanth KU, Chundawat RS, Nichols JD, Kumar NS (2004) Estimation of tiger densities in the tropical dry forests of Panna, Central India, using photographic capture-recapture sampling. Anim Conserv 7(3):285-290

KIMS (2007) Performance audit of animal birth control programme in Bangalore city. A report. http://kimscommunitymedicine.org/ activities/. Accessed 8 January 2019

Matter HC, Daniels TJ (2000) Dog ecology and population biology. In: Macpherson CNL, Meslin FX, Wandeler AI (eds) Dogs, Zoonoses and public health. CABI Publishing, New York, pp 17-62

Menezes R (2008) Rabies in India. Can Med Assoc J 178:564-566. https://doi.org/10.1503/cmaj.071488

Morters MK, McKinley TJ, RestifO et al (2014) The demography of free roaming dog populations and applications to disease and population control. J Appl Ecol 51:1096-1106. https://doi.org/10.1111/13652664.12279

Pal SK, Ghosh B, Roy S (1998) Dispersal behaviour of free-ranging dogs (Canis familiaris) in relation to age, sex, season and dispersal distance. Appl Anim Behav Sci 61:123-132. https://doi.org/10.1016/ S0168-1591(98)00185-3

QGIS Development Team (2018) QGIS geographic information system. Open Source Geospatial Foundation Project. http://qgis.osgeo.org

R Core Team (2016) R: a language and environment for statistical computing. R Foundation for Statistical Computing, Vienna https:// www.R-project.org/

Reese JF (2005) Dogs and dog control in developing countries. In: Salem DJ, Rowan AN (eds) The state of the animals III: 2005. Humane Society Press, Washington, DC, pp 55-64

Sharma M (2019) Steep rise in stray dogs in Bengaluru, shows census. Deccan Herald. https://www.deccanherald.com/city/focusbengaluru/steep-rise-in-stray-dogs-in-bengaluru-shows-census788491.html. Accessed 24 March 2020

Sudarshan MK, Madhusudana SN, Mahendra BJ et al (2007) Assessing the burden of human rabies in India: results of a national multicenter epidemiological survey. Int J Infect Dis 11:29-35. https:// doi.org/10.1016/j.ijid.2005.10.007

Sudarshan MK, Mahendra BJ, Madhusudana SN et al (2006) An epidemiological study of animal bites in India: results of a WHO sponsored national multi-centric rabies survey. J Commun Dis 38:32-39

Tiwari HK, Robertson ID, O’Dea M, Gogoi-Tiwari J, Panvalkar P, Bajwa RS, Vanak AT (2019) Validation of application SuperDuplicates (AS) enumeration tool for free-roaming dogs (FRD) in urban settings of Panchkula municipal Corporation in North India. Frontiers in Veterinary Science 6:173. https://doi.org/10.3389/fvets.2019.00173

Tiwari HK, Vanak AT, O'Dea M, Gogoi-Tiwari J, Robertson ID (2018) A comparative study of enumeration techniques for free-roaming dogs in rural Baramati, district Pune, India. Frontiers in Veterinary Science 5:104. https://doi.org/10.3389/fvets.2018.00104

Totton SC, Wandeler AI, Zinssta J, Bauch CT, Ribble CS, Rosatte RC, McEwen SA (2010) Stray dog population demographics in Jodhpur, India following a population control/rabies vaccination program. Preventive Veterinary Medicine 97:51-57. https://doi.org/10.1016/ j.prevetmed.2010.07.009

Wickham H (2016) ggplot2: elegant graphics for data analysis. SpringerVerlag, New York. ISBN 978-3-319-24277-4, https://ggplot2. tidyverse.org/ 